\title{
Introduction of eLectures at the Medical University of Graz - Results and Experiences from a Pilot Trial
}

\author{
http://dx.doi.org/10.3991/ijet.v8iS1.2330 \\ Herwig Rehatschek, Ariane Aigelsreiter, Peter Regitnig, Barbara Kirnbauer \\ Medical University Graz, Graz, Austria
}

\begin{abstract}
In autumn 2011 we developed a concept for a new service to be offered for our teachers in connection with virtual lessons: eLectures. eLectures in general are defined as recorded lectures. We offer two kinds of services: InfoSnippets and InfoCasts. InfoSnippets represent short videos visualizing practical skills to be learned by medical students such as measuring the blood pressure or how to make a surgical suture. InfoCasts are recordings of entire lectures including interactive elements. Basic InfoCasts consist of voice recording in combination with synchronized slides. Video is offered only in form of short sections where e.g. practical skills or experiments are shown. With begin of summer semester 2012 we started with four pilot projects of lessons which were fully virtualized. In this paper we present the concept for our eLectures, the selection process of the production software, the realization of the four pilot projects and the evaluation results of the students.
\end{abstract}

Index Terms-eLearning, streaming lessons, virtual classroom, new learning applications, multimedia applications

\section{INTRODUCTION AND BACKGROUND}

The Medical University of Graz runs for more than 10 years its eLearning platform VMC (Virtual Medical Campus) [1]. In 2010 the third software platform - the open source system Moodle [2] - was installed and serves more than 4300 students a year. From the very start of the eLearning platform we used a blended learning concept with a mixture of presence and pure virtual lessons. In 2005 even a full semester was virtual [3]. With begin of SS2012 $9.8 \%$ of the curriculum human medicine is offered virtually, which corresponds to approximately 29.4 semester hours. The execution of virtual lessons is fully automated by means of a special add on module (called MOMOS) developed for VMC/Moodle. MOMOS automatically generates tasks of virtual lessons for registered students and transmits at the end of the course a mark to our central administration system [4], [5], [6].

In autumn 2011 we developed a concept for a new service to be offered for our teachers in connection with virtual lessons: eLectures. eLectures in general are defined as recorded lectures. We offer two kind of services: InfoSnippets and InfoCasts. InfoSnippets represent short videos visualizing practical skills to be learned by medical students such as measuring the blood pressure or how to make a surgical suture. InfoCasts are recordings of entire lectures. Here we offer voice recording in combination with the synchronized slides. Video is offered only in form of short sections where e.g. practical skills or experiments are shown. Since it does not add any additional value (and to save storage space) the video of the teacher speaking the lesson is not provided.

The concept for eLectures was finalized 2011. With begin of summer semester 2012 we started with four pilot projects of lessons which were fully virtualized. Next to the concept of eLectures we used for three of the projects also our virtual microscope. A virtual microscope [7], [8] offers the same functionality than a physical one, however, needs digitized objects for display. It enables the access of hundreds of students in parallel 24/7 and dramatically reduces costs in comparison to buying physical devices.

In this paper we present the concept for our eLectures, the selection process of the production software, the realization of the four pilot projects and the evaluation results of the students. In order to avoid misunderstandings regarding terminology to be used within this paper we clearly distinguish between the following terms:

- eLectures: recorded lectures which are permanently stored and can be watched by students at any time via access to our eLearning platform. Content cannot be downloaded for off line viewing.

- podcasts and vodcasts: like eLectures, however, content can be additionally downloaded to PC and/or mobile devices, hence the student does not need a permanent Internet connection for watching the lesson.

- streaming content: live broadcasts of lectures which can be watched synchronously to the presentation of the teacher by students via a standard web browser with an appropriate streaming plugin. The content is usually not permanently stored for later usage.

\section{STATE OF THE ART}

On a national level (Austria) at least twelve universities are actively involved in the realization of eLectures and streaming content [9] as stated in a publication of the working group "streaming technology and learning innovation" from the forum for new media Austria (FNMA) [10] including the Medical University of Graz. The development stages range from pioneer phase, expansion stage to operational phase. The only university in Austria having a fully automated recording workflow is the University of Vienna. Their solution involves fixed mounted cameras within the lesson rooms, in combination with a self developed software solution. The software allows teachers easily to start the recording service right before the start of the lesson. Teachers have the choice 
between streaming content (live broadcast), eLectures (recording of the lesson) or both. When the recording of the lesson is finished a link to the media file is distributed to the teacher, which can be directly incorporated in the eLearning platform so that students have from now on permanently access to the eLecture.

On an international level a vast number of universities and educational institutions provide eLectures. Many well known universities such as MIT [11], The Open University [12] and the Yale University [13] provide their eLectures also free of charge for the general public which is better known under the term "open educational resources (OER)" - under creative common licenses.

\section{HuRDLES AND MOTIVATION FACTORS FOR ELECTURES}

Resulting from the experiences various hurdles have been identified by universities in Austria which might hinder the successful introduction of eLectures. For each hurdle an appropriate action is provided which should compensate it. On the contrary also typical motivation factors and clear advantages for eLectures are stated in the second part of this chapter.

\section{A. hurdles}

Uncontrolled distribution of content: many teachers are afraid that once the eLecture is available it will be downloaded by students and distributed on various Internet servers such as YouTube. Teachers are afraid of manual modifications of the content in connection with damage of reputation. Compensation: downloading can be technically prohibited or at least made difficult for technically inexperienced users. Furthermore this can be legally supressed by introducing a house right which has to be signed by all students.

Empty lecture rooms: many teachers are afraid that in case an eLecture is provided nobody will visit their classroom lesson anymore. Compensation: this fear is usually baseless due to the fact in case a lecture room is really empty the quality of the lecture shall be critically investigated. The majority of students wants eLectures in addition to normal lectures so that they can use it for the proper preparation for exams. Students can listen again to parts of the lecture where they had difficulties during the presence part. A complete substitution of presence lessons by eLectures is only wanted by a small amount of students including persons with special needs and students having children to look after. All surveys and evaluations known by the authors clearly state that students prefer a blended learning concept rather than a pure virtual one.

Unclear legal framework: according to the Austrian law teachers are allowed to use within classroom lessons different materials than they are allowed to use in eLectures. E.g. the use of copies from books is allowed during a classroom lesson, but a scan of these may not be used within an eLecture which is uploaded on a server, even if the access is limited. Hence for video recordings and slides it must be clear what is allowed. Compensation: when uploading content all rights must be cleared. In worst case pictures shown during the classroom lesson cannot be shown at the eLecture. Alternatively the images may be licensed or images may be produced by the eLearning support team.

Feeling uncomfortable in front of a camera: some teachers say that they feel very uncomfortable when speaking in front of a camera. Compensation: this can be compensated by providing special training courses for teachers e.g. presentation skills and rhetoric courses.

Insufficient technical know-how and/or personal resources: some teachers are afraid to produce eLectures due to lack of technical experience. Compensation: in order to successfully introduce eLectures the university must provide appropriate personnel which supports the teachers during the entire production process. The investment for nearly $100 \%$ automatic recording solutions is quite high, but even those solutions still need support personnel. At the Medical University of Graz we have an own department for supporting teachers with one person (75\%) dedicated for eLectures.

\section{B. motivation factors}

Specifically for the Medical University Graz there exists a guideline for virtual lessons. According to this guideline teachers must provide for virtual lessons a scriptum and a web based training (multiple choice questions). Having recorded an eLecture no scriptum has to be provided anymore. Hence the recording of an eLecture significantly reduces the work to be done by teachers in order to establish a pure virtual lecture.

According to surveys eLectures are a strong wish by students who see this already as a standard and not as a nice to have. Students mostly use eLectures for a proper preparation for the exam.

eLectures make the exchange of knowledge and experiences easier. Teachers from other universities can also have remote access on the lectures and provide their comments and feedback.

Especially for part time studies (next to the job) eLectures are a very valuable instrument for students to learn from any place at any time. In these studies a specific percentage of pure virtual lessons is usually highly welcome.

Last but not least the quality of professionally produced eLectures is much higher than those produced by students with e.g. mobile devices on their own initiative.

\section{SELECTION OF THE PRODUCTION SOFTWARE ENVIRONMENT}

As stated in chapter I we distinguish between eLectures, pod- and vodcasts and streaming content. For the latter the technical requirements - especially in connection with available bandwidth - are very high, however, the Medical University of Graz currently has no need to provide streaming content (live broadcasts) due to its limited number of students per year. Streaming content is mostly needed at universities who have huge and unpredictable amounts of students a year hence problems with available lesson room capacities.

So we decided for a first pilot trial to go for eLectures to be produced by a mobile recording solution in combination with an appropriate software production environ- 
ment. For the pilot trial we went for a format which combines audio recording of the lecture with synchronized slides. The abandonment of a video of the teacher speaking the lesson within the eLecture format can be argued that such a video will not contribute to increase the learning curve of the students but will result in the need of much more disk space. For visualization of the teacher a photo is sufficient. In case medical skills or experiments are shown by the teacher we insert short video sequences into the eLecture. In Figure 1 an example of an eLecture produced with Adobe Captivate is given.

After the definition of the format we defined criteria for the eLecture production software environment in order to perform an appropriate market overview. All in all we defined 14 criteria including licensing costs. Within the market overview we identified the following software environments suitable for us: Lecturnity [14], Lecturio [15], Presentations2Go [16], Camtasia Studio 7 [17] and Adobe Captivate [18]. (Table I)

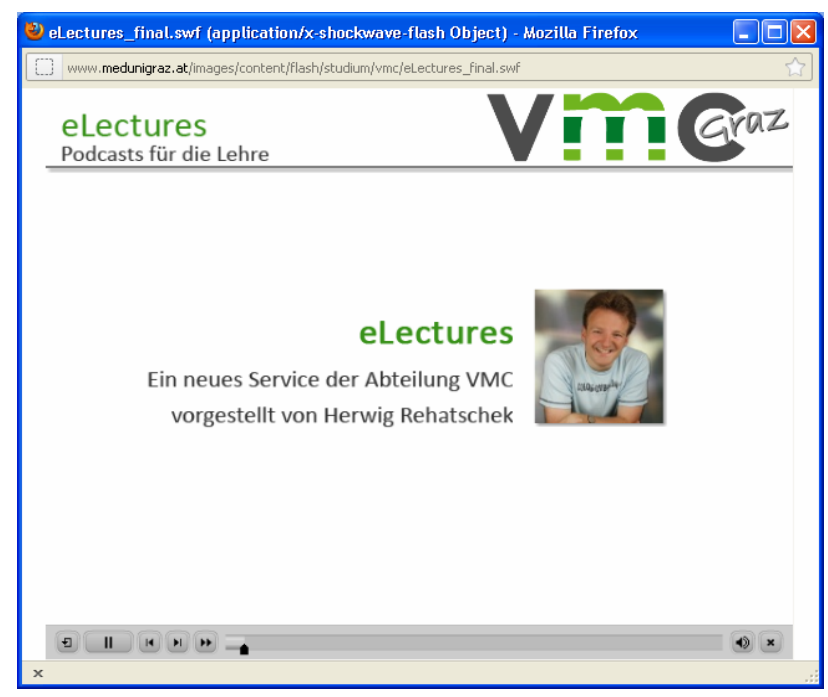

Figure 1: example of an eLecture

TABLE I. COMPARISON AND EVALUATION OF PRODUCTION ENVIRONMENTS FOR E-LECTURES

\begin{tabular}{|c|c|c|c|c|c|}
\hline & \multicolumn{5}{|c|}{ Products } \\
\hline & Lecturnity & Lecturio & Presentations 2 Go & Camtasia Studio 7 & $\begin{array}{c}\text { Adobe Cap- } \\
\text { tivate }\end{array}$ \\
\hline $\begin{array}{l}\text { SW generates a format to be easily integrated into } \\
\text { web applications (preferably flash) }\end{array}$ & Yes & $\mathrm{Yes}^{1}$ & Yes $^{2}$ & $\mathrm{Yes}^{3}$ & $\mathrm{Yes}^{3}$ \\
\hline Synchronization of slides, audio and video & Yes & Yes & Yes & Limited $^{4}$ & Yes \\
\hline $\begin{array}{l}\text { Layout of result variable and individually configur- } \\
\text { able by user }\end{array}$ & $\mathrm{Yes}^{5}$ & $\mathrm{Yes}^{6}$ & Yes $^{7}$ & Limited $^{8}$ & Yes $^{9}$ \\
\hline Necessary plugins for web browser & $\begin{array}{l}\text { Flash, Real Player, } \\
\text { Media Player }\end{array}$ & Flash, Java & \begin{tabular}{|l|} 
Silverlight, Media \\
Player 9
\end{tabular} & \begin{tabular}{|ll} 
Flash, & Media \\
Player & \\
\end{tabular} & Flash \\
\hline Automatic indexing for text search & Yes $^{10}$ & Nein $^{11}$ & No & No & Yes \\
\hline Structure view & $\mathrm{Yes}^{12}$ & Yes & Yes & No & Yes \\
\hline Video recording integrated & $\mathrm{Yes}^{13}$ & $\mathrm{Yes}^{14}$ & $\mathrm{Yes}^{15}$ & $\mathrm{No}^{16}$ & $\mathrm{Ja}$ \\
\hline Recording of the desktop or parts of it & Yes & Yes & Yes & Yes & Yes \\
\hline Suitable for streaming content (live events) & Yes & No & Yes $^{17}$ & No & Yes \\
\hline Academic customers & Yes $^{18}$ & Yes $^{19}$ & $\mathrm{Yes}^{20}$ & N/A & Yes $^{21}$ \\
\hline Source Code of WebContainer available & No & $\mathrm{No}^{22}$ & No & No & Yes \\
\hline $\begin{array}{l}\text { Software to be used without additional technical } \\
\text { personnell }\end{array}$ & Yes & No & Yes & Yes & $\mathrm{No}^{23}$ \\
\hline Tools for editing provided & Yes & $\mathrm{Yes}^{24}$ & Yes & Yes & Yes \\
\hline License costs & $152 €^{24}$ & $250 € /$ month $^{26}$ & $499 €^{27}$ & $145 €^{28}$ & $125 €^{29}$ \\
\hline Overall rating (1 - 5 Smilies) & (;) $: ;)(;)$ & (;) & ;:) & (:) $:-;$ & (:);:;);:; \\
\hline
\end{tabular}

${ }^{1}$ ) only in Java and for additional costs. Lecturio offers an own LMS with already existing eLearning content. Each customer receives its own private area within this LMS.

${ }^{2}$ ) but only Microsoft Silverlight, no Flash

$\left.{ }^{3}\right)$ and various other formats

$\left.{ }^{4}\right)$ software records the screen - the video to be recorded must be visible in a separate window on the screen.

${ }^{5}$ ) language can be changed, variable size of browser window, search function, variable size of video

${ }^{6}$ ) content of windows can be defined by user, additional functionality such as forums provided.

${ }_{8}^{7}$ ) Layout and language can be changed, embedding possible

${ }^{8}$ ) hotspots can be defined within flash animations in order to provide interactivity

9) since this is a visual "programming" environment it provides a vast number of layouts

${ }^{10}$ ) indexing is done directly from the slides or provided text. The software cannot analyze/index audio (speech recognition).

${ }^{11}$ ) recorded lessons are sent to the Lecturio server where they are further processed. On the platform comments and tags can be added.

${ }_{22}$ ) will be automatically generated

${ }^{13}$ ) a video can be added later as well. Webcam and visualizer are easily to be integrated, problematic is switching amongst different video sources.

${ }^{14}$ ) Lecturio offers a knapsack with a notebook, a camera and a microphone. This equipment is especially designed to be used by technically inexperienced users.

$\left.{ }^{15}\right)$ per webcam
${ }^{16}$ ) Camtasia does not accept external video sources, however, video can be recorded directly from the screen when played within a window without using hardware acceleration.

${ }^{17}$ ) for streaming content an extra - very expensive - streaming server hast to be bought

${ }^{18}$ ) more than 60 universities use Lecturnity including: CME Webakademie, Friedrich Schiller Universitätsklinikum Jena, Klinikum Dortmund $\mathrm{GmbH}$, Universitätsklinikum Bonn, Universitätsklinikum Ulm, Universitätsklinikum Regensburg, Universitätsklinikum Schleswig Holstein

$\left.{ }^{19}\right)$ Lecturio even offers a pool with various lectures from the medical area (e.g. bio chemistry, anatomy, bio physics, physiology)

$\left.{ }^{20}\right)$ especially from the area medicine and health care.

$\left.{ }^{21}\right)$ e.g. University of Technology Vienna, Züricher Hochschule (ZHAW)

${ }^{22}$ ) eLectures are only offered via the Lecturio platform, no local download possible.

${ }^{23}$ ) Flash programmer needed

${ }^{24}$ ) only extern, no tools for local installation

${ }^{25}$ ) costs of a single user version. Discount for academic users, also campus license possible in case it should be used by many teachers.

${ }^{26}$ ) minimum: 3 months, otherwise: $350 €$. The knapsack with the complete recording equipment is $990 € /$ semester including editing of 12 eLectures and hosting. $99 €$ per year for embedding videos into local websites (discount possible for a huge number of videos).

${ }^{27}$ ) lite version for a single user license without broadcasting and multiple sources features.

${ }^{28}$ ) academic license, price for $1-4$ licenses. Discount possible when buying $>5$ licenses.

${ }^{29}$ ) single user license. 


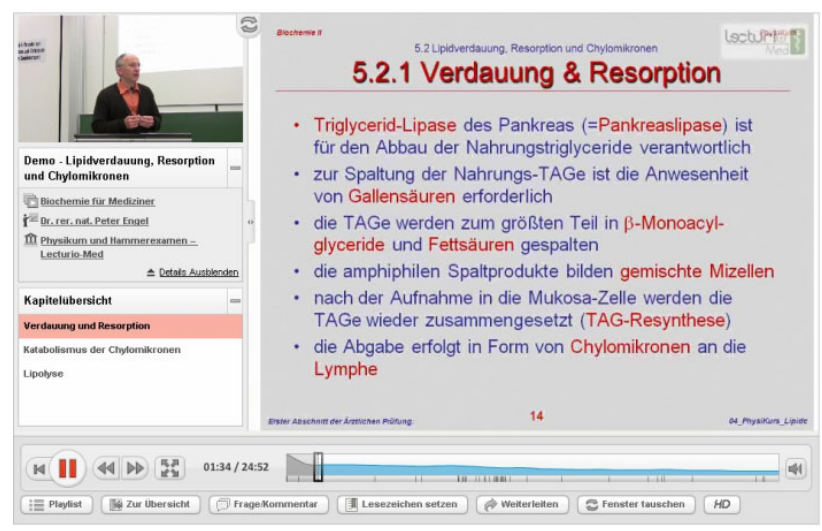

Figure 2: eLecture recorded with Lecturio

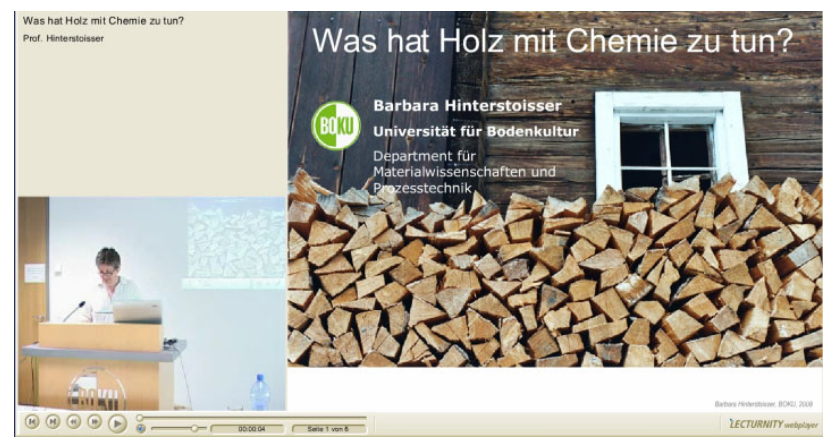

Figure 3: eLecture viewer of Lecturnity

Figures 2 and 3 visualize some example lessons realized with Lecturio and Lecturnity.

Adobe Captivate was the winner in this market survey because it fit best our requirements and the results can be smoothly integrated into our learning management system VMC/Moodle. Adobe Captivate does not require any programming skills, it works like a graphical layout tool where authors can insert interactive elements. This tool is especially designed for creative people already familiar with Adobe products such as Illustrator and Photoshop. Since we are already working with Adobe products for many years this product was quite easy to use for us. The academic license of Adobe products guaranteed very low license costs. Furthermore the software offers integration of Powerpoint, Questionmark Perception [19] and is also available on the Mac. It allows the generation of content for the iPad and perfectly integrates with all other Adobe products we are using.

\section{REALIZATION}

Within the summer semester 2012 we realized four eLecture pilot trials on the following medical subjects: histology-pathology exercises (two eLectures), pathology of endometrial cancer and oral surgery. All these projects are a combination of eLectures, learning documents, videos and interactive elements such as virtual microscopes. In Figure 4 the realization of one of the two histology-pathology exercises is visualized. In the upper part a virtual microscope with two training markers is given, indicating areas of special interest for the students. These areas are explained in more detail within the eLectures coming along with this virtual lesson. One page of such an eLecture is given on the lower part of Figure 4. Students can control the player and listen to the audio explanations given by the teacher combined with slides synchronously displayed.
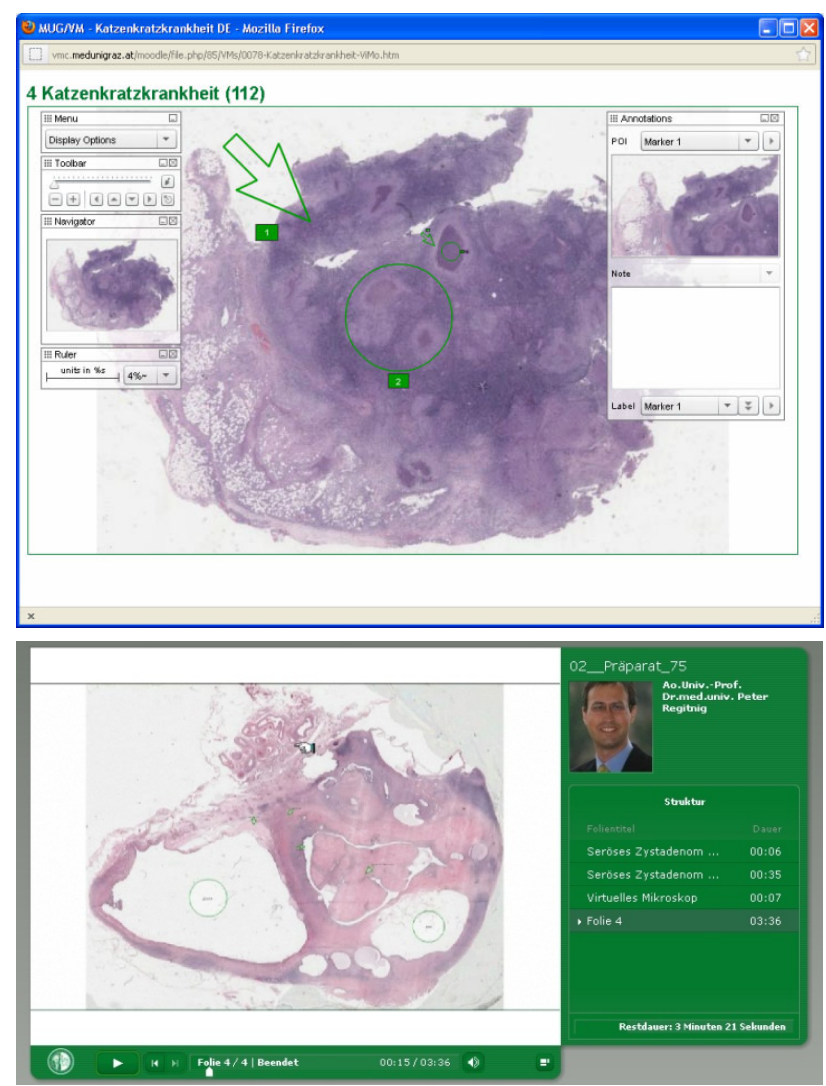

Figure 4: example of one of the four eLecture pilot trials - a virtual microscope combined with an eLecture within the histology-pathology exercise realized with Adobe Captivate

Furthermore also the structure of the lesson is displayed on the right side just below the picture of the teacher. By clicking on these chapters students can directly navigate to those parts of the eLecture they are specifically interested in.

The histopathology exercise includes next to the eLecture also virtual microscope applications where students can navigate, zoom in and out within the object and visualize by the teacher predefined markers with explanations. The software realization of this virtual microscope at the Medical University of Graz was done in 2011 [7], [8].

The technical realization of the eLectures was a close cooperation between the department "virtual medical campus" (VMC) and the teachers. The first step for the eLecture was the design of the storyboard by means of the elements to be used and the power point slides to be shown. Once the power point slides where ready, teachers received a digital audio recording device. They recorded their lesson and gave after each slide clear editorial instructions for the post processing, e.g. "next slide", "now following slide 10". The department VMC developed the flash container with the interactive elements by utilizing Adobe Captivate. After successful recording the teacher sent the audio file to the department VMC, where we manually synchronized the audio with the slides.

Next to the virtual microscopes our pilot eLectures did also contain other interactive elements such as videos and web based trainings (multiple choice questions which students had to answer compulsory in order to pass the eLecture lesson). The starting point for the students was in all cases the eLecture, which served like a table of con- 
tents. From there the various elements where linked and the students explored the content piece by piece. All these pieces where embedded within our learning management system VMC/Moodle, which was the central access point for the students.

Last but not least for each of the four pilot eLectures an online evaluation was generated which the students could fill in voluntarily. The results of this evaluation are presented in the next chapter.

\section{EVALUATION RESULTS}

For all four pilot trials an online evaluation with the same questions where performed. The evaluation contained 7 closed and 2 open questions giving students the possibility to provide extensive feedback for potential improvement.

The two most representative evaluation results where those of the two histology pathology exercises because they were mandatory lessons which students had to execute in order to continue with their study. Hence those exercises featured the highest return rates for the evaluation. Additionally in both exercises the highest number of students participated which resulted in clear and meaningful evaluation results. The results are presented in the next two sub chapters.

\section{A. histology-pathology exercise 1}

From a total of 336 participating students 75 feedbacks were returned which results in a return rate of $22.32 \%$.

Question \#1: I want the histology-pathology exercise in the future

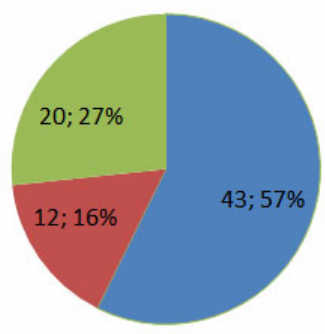

I offered purely virtual without presence part

Eoffered purely virtual without presence part but with improvements

m not as electure but as a normal lesson

Question \#2: During execution of the eLecture my questions per E-mail to the teacher where immediately answered.

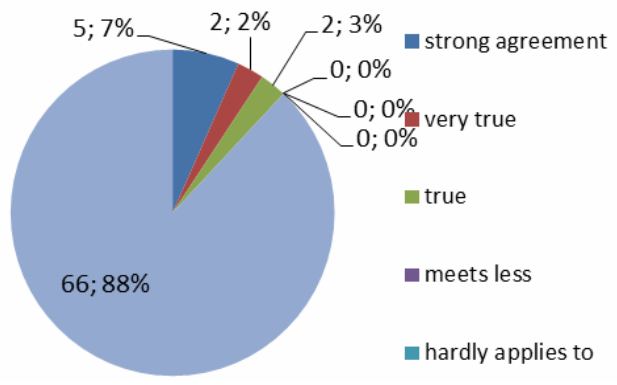

Question \#3: I executed the eLecture

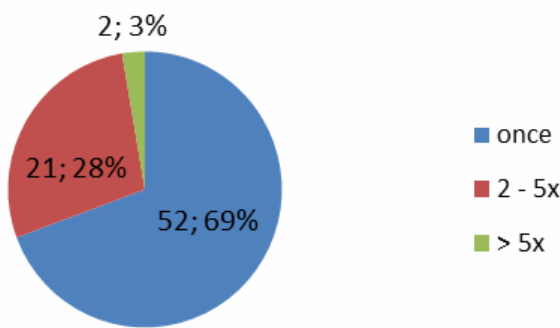

Question \#4: from my current perspective it is very likely that the eLectures are also of use at a later stage in the study.

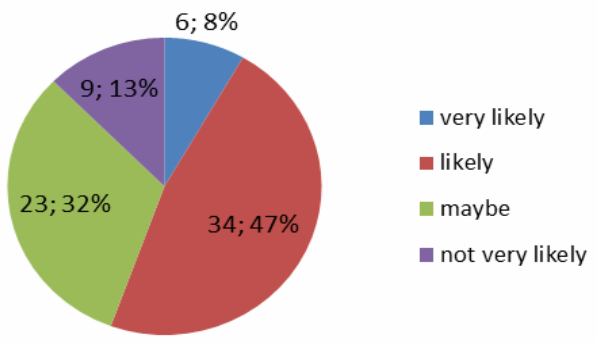

Question \#5: I executed the eLecture

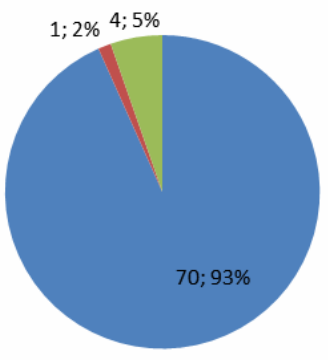

ש on my private PC/Laptop at home

n on my mobile device (SmartPhone, iPad, Laptop etc.)

n on a PC provided by the University

Question \#6: For the future I would like to have more purely virtual lectures

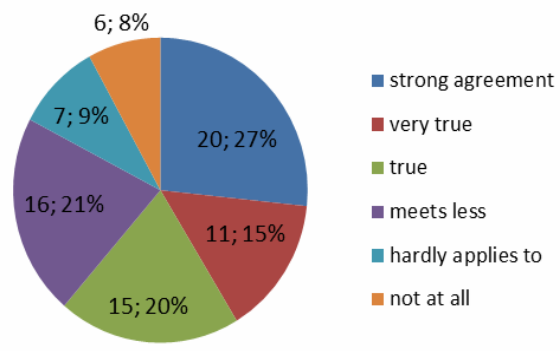

Question \#7: eLectures provided via the LMS $\mathrm{VMC} /$ Moodle are essential for my learning success.

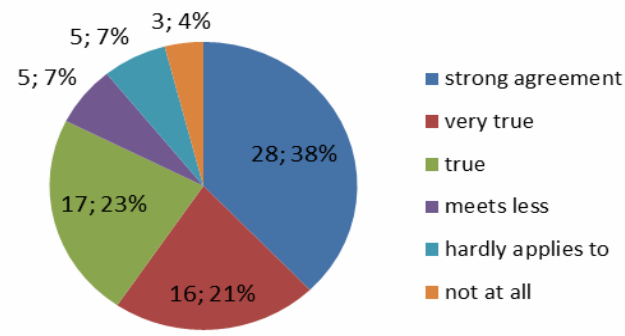




\section{B. histology-pathology exercise 2}

From a total of 336 participating students 57 feedbacks were returned which results in a return rate of $16.97 \%$.

Question \#1: I want the histology-pathology exercise in the future

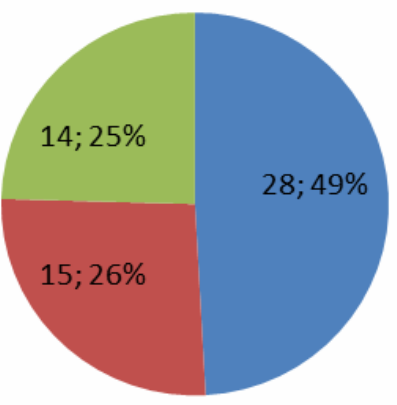

घ offered purely virtual without presence part

affered purely virtual without presence part but with improvements

not as electure but as a normal lesson

Question \#2: During execution of the eLecture my questions per E-mail to the teacher where immediately answered.

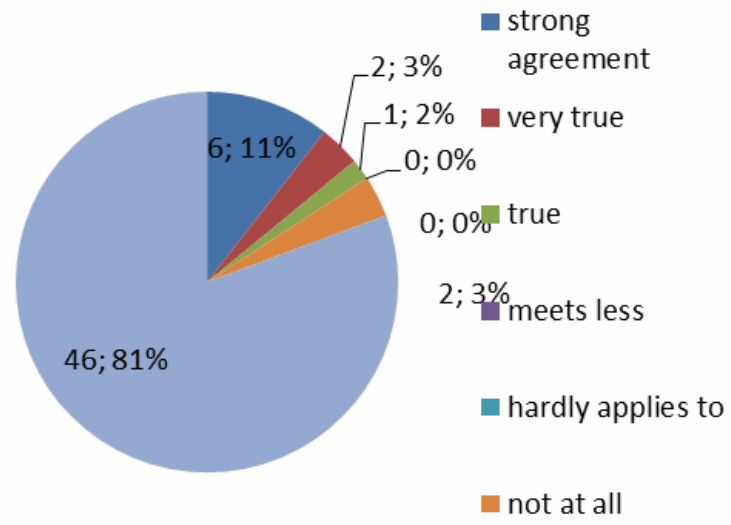

Question \#3: I executed the eLecture

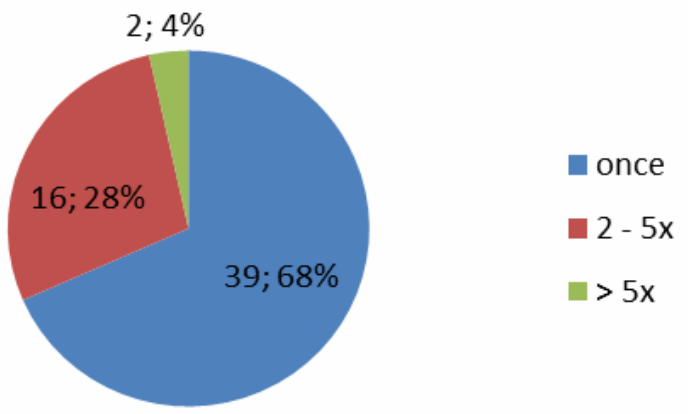

Question \#4: from my current perspective it is very likely that the eLectures are also of use at a later stage in the study.

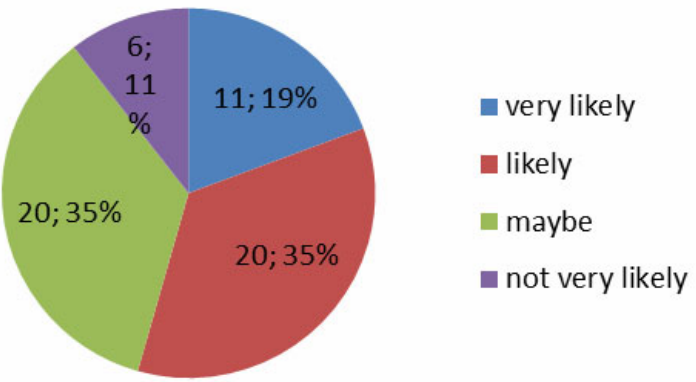

Question \#5: I executed the eLecture

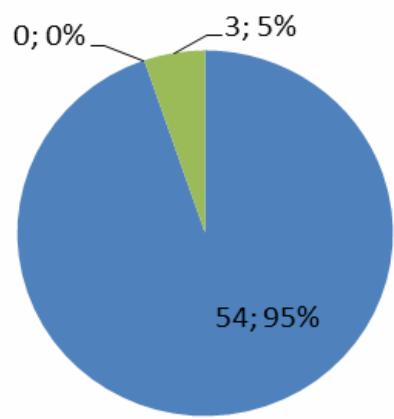

$$
\begin{aligned}
& \text { on my private } \\
& \text { PC/Laptop at } \\
& \text { home } \\
& \text { on my mobile } \\
& \text { device } \\
& \text { (SmartPhone, } \\
& \text { iPad, Laptop etc.) } \\
& \text { on a PC provided } \\
& \text { by the University }
\end{aligned}
$$

Question \#6: For the future I would like to have more purely virtual lectures

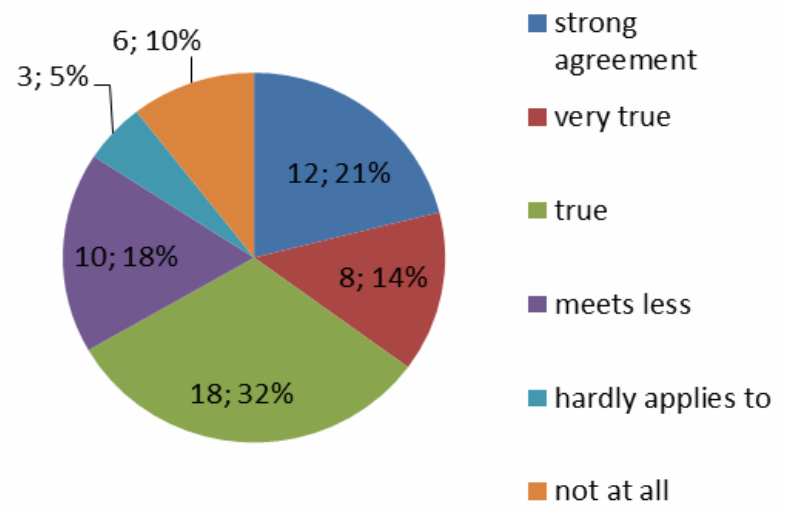

Question \#7: eLectures provided via the LMS $\mathrm{VMC} /$ Moodle are essential for my learning success.

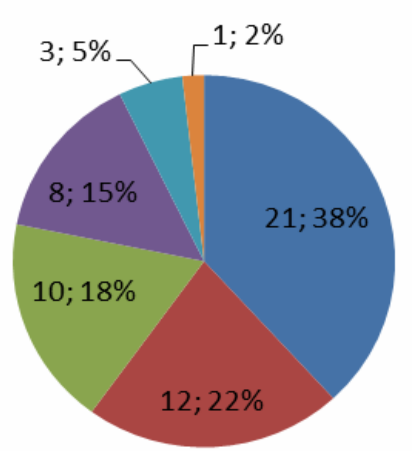

strong agreement

very true

a true

meets less

- hardly applies to

not at all 


\section{C. general feedback}

Within the two open questions we asked students what they would like to have improved and what further comments they have.

The majority of students reported that they were happy to have a purely virtual lesson offered as eLecture. Clear advantages included execution at any time, saving of time, no need to be present at the campus, the possibility to repeat the eLecture and to have it available also later during the study.

The virtual microscope within the eLecture was highly welcome because it offers the interactivity of a real microscope and simultaneously the advantage to execute it from home.

Some students demanded an offline version so that they can watch the lesson also in places where no Internet connection is available. Very few students wanted a personal contact to the teachers.

Many students were grateful for the very complex implementation of the eLecture with many interactive elements in comparison to standard virtual lessons which normally consist of a PDF script and a web based training.

\section{EXPERIENCES AND CONCLUSIONS}

When introducing a new software for the production of eLectures we can strongly emphasize to clearly define the requirements and needed features beforehand and then to perform a market analysis in order to identify the most suitable solution for your environment. From our experience a production of eLectures solely by teachers without any technical support is not feasible besides you have only teachers which are familiar with AV devices, video and audio software tools and have enough time to produce the eLectures.

For calculation of time resources needed the following rule of thumb is helpful The overall production time for one eLecture consists of three phases: preparation phase, recording phase, post production phase. The preparation phase is optional but in most cases necessary, especially for more complex eLectures such our 4 pilot trials where the eLectures consisted of several multimedia objects. Within this phase the framework shall be fixed, at least the structure (chapters) of the eLecture must be defined. The recording phase will take at least the time the real lesson takes, in praxis it will take longer due to slips of the tongue, unexpected background noises and so on which will cause a re-recording. In the post processing phase the editing will take place and the eLecture will be produced in its final viewing format. Depending on how much effort you want to invest (e.g. adding the structure, adding subtitles, adding interactive elements) this phase can take 1 to 4 times the length of the actual lesson.

From the evaluation results we could derive very valuable feedback. About $75 \%$ of the students want the currently implemented 4 pilot trials to be offered purely virtual as eLecture (improvements were given). 85\% did not even use the contact feature via E-mail and a few mentioned that they even did not know from this feature. From this we derive that the eLectures are very selfexplanatory. $28 \%$ executed the eLecture between 2 and 5 times. This underlines the usefulness of eLectures which provide students the possibility to repeat parts of a lecture as often as needed in order to understand the content properly. For $55 \%$ it is very likely or at least likely that they will use the eLectures also at later stages of their study which justifies the efforts we invested to produce the eLectures. The overwhelming part of the students, $94 \%$, executed the eLectures from home giving them a maximum of flexibility in planning their time schedule. After all $63 \%$ of the students voted for an extension of the pure virtual lessons in the form of eLectures which is very encouraging for us because in human medicine most students are according to our experiences very sceptical to $100 \%$ virtual lessons. Of course we will further follow a blended learning concept, however, it will be a combination of pure virtual lessons and classroom lessons. Last but not least $79 \%$ (!) of the students regard eLectures as essential for their learning success.

From the open questions testimonials such as given below clearly state that we are in the right way for the future.

The very complex implementation of the eLectures makes it comparable to a normal classroom lesson.

In my opinion I learned from these eLectures more than from a classroom lesson because I could personally execute all elements with my individual speed.

I'm very grateful for this new format of visualizing pathology-histology objects!

I personally liked the virtual eLecture due to the fact I have more time to perform it and for my personal learning style I need a lot of repeats.

This eLecture saves time and gives additionally the possibility to repeat it right before taking the exam.

Thanks, this was an ingenious exercise which was much more interesting than sitting in the lecture room!

\section{REFERENCES}

[1] Smolle J, Staber R, Jamer E, Reibnegger G.: „Aufbau eines universitätsweiten Lern- Informationssystems parallel zur Entwicklung innovativer Curricula - zeitliche Entwicklung und Synergieeffekte“. In: Tavangarian D, Nölting K, editors. Auf zu neuen Ufern - E-Learning heute und morgen. Münster New York München Berlin: Waxmann, 2005: 217-226. Ref ID: 9019

[2] Moodle - Modular Object Oriented Dynamic Learning Environment, open source LMS, <URL: http://www.moodle.org>

[3] Smolle J, Staber R, Hye F, Jamer E, Macher S, Neges H et al.: "ELearning in the First SEMESTER of an Undergraduate Medical Curriculum.”, 2006. EDEN conference proceedings. Ref Type: Electronic Citation Ref ID: 9210, <URL: http://www.edenonline.org/contents/conferences/submit/upload/Smolle.doc $>$

[4] H. Rehatschek, G. Hölzl, M. Fladischer: "The set-up and implementation of fully virtualized lessons with an automated workflow utilizing VMC/Moodle at the Medical University of Graz". In proceedings of the 14th conference on interactive collaborative learning (ICL), pp. 5 - 9, ISBN 978-1-4577-1746-8, 21 - 23 September 2011, Piešt'any, Slovakia.

[5] H. Rehatschek, G. Hölzl, A. Hruska: "The seamless integration of virtualized lessons with a fully automated workflow into the LMS VMC/Moodle of the Medical University of Graz". Online Proceedings of the MoodleMoot 2011 conference, 24 - 25 February 2011, Vienna, Austria.

[6] H. Rehatschek, R. Staber, H. Neges, G. Reibnegger, J. Smolle: "The blended learning concept of the Medical University of Graz and its technical realization". In proceedings of the 13th Interactive Computer Aided Learning conference, pp. 54 - 59, ISBN 9783-89958-541-4, 15 - 17 September, 2010, Hasselt, Belgium

[7] Herwig Rehatschek, Florian Hye: "The introduction of a new virtual microscope into the eLearning platform of the Medical University of Graz". International Journal of Online Engineering (iJoe), ISSN 1868-1646, Volume 7, Issue 4, November 2011, pp. $36-41$ 
[8] H. Rehatschek, F. Hye: "A new virtual microscope at the Medical University of Graz ". In the proceedings of the 17 th international conference on technology supported learning \& training (online educa), pp. 193 - 197, ISBN 978-3-941055-13-1, 29 November - 2 December 2011, Berlin, Germany.

[9] A. Lorenz: "Universities on Air". In the proceedings of the 14th international conference on interactive collaborative learning (ICL 2011), pp. 656 - 664, ISBN 978-1-4577-1746-8, 21 - 23 September 2011, Piestany, Slovakia.

[10] Forum for new Media Austria (FNMA), homepage. <March 2012 / URL: http://www.fnma.at>

[11] MITopenCourseware, Massachusetts Institute of Technologyn (MIT), homepage. <March 2012 / URL: http://ocw.mit.edu/courses/audio-video-courses/>

[12] Learning Space, The Open University, homepage. <March 2012 / URL: http://openlearn.open.ac.uk/>

[13] Open Yale Courses, Yale University, homepage. <March 2012 / URL: http://oyc.yale.edu/>

[14] Lecturnity, recording software for lectures, homepage. <June 2012 / URL: http://www.lecturnity.de>

[15] Lecturio, online learning, homepage. <June 2012 / URL: http://www.lecturio.de/>
[16] Presentations2Go, interactive lecture capturing and webcasting, homepage. <June 2012 / URL: http://www.presentations2go.eu/>

[17] Camtasia Studio 7, screen recording software, homepage. <June 2012 / URL: http://www.camtasiastudio.at/camtasia-studioscreen-recorder/index.htm>

[18] Adobe Captivate, creating interactive eLearning, homepage. $<$ June 2012 / URL: http://www.adobe.com/products/captivate.html >

[19] Questionmark Perception, assessment management software, homepage. <July 2012 / URL: https://www.questionmark.com>

\section{AUTHORS}

Herwig Rehatschek, Ariane Aigelsreiter, Peter Regitnig, and Barbara Kirnbauer are with the Virtual Medical Campus, Institute of Pathology, University Clinic of Dentistry, Medical University Graz, Graz, Austria. \{Herwig.Rehatschek, Ariane.Aigelsreiter, Peter.Regitnig, Barbara.Kirnbauer\}@medunigraz.at

This article is an extended and modified version of a paper presented at the International Conference on Interactive Collaborative Learning (ICL2012), held 26 - 28 September 2012, in Villach, Austria. 